University of Nebraska - Lincoln

DigitalCommons@University of Nebraska - Lincoln

\title{
Attributions of Blame in a Hypothetical Child Sexual Abuse Case: Roles of Behavior Problems and Frequency of Abuse
}

\author{
Kate Theimer \\ University of Nebraska-Lincoln, katetheimer4@gmail.com \\ David J. Hansen \\ University of Nebraska - Lincoln, dhansen1@unl.edu
}

Follow this and additional works at: https://digitalcommons.unl.edu/psychfacpub

Part of the Child Psychology Commons

Theimer, Kate and Hansen, David J., "Attributions of Blame in a Hypothetical Child Sexual Abuse Case: Roles of Behavior Problems and Frequency of Abuse" (2020). Faculty Publications, Department of Psychology. 1006.

https://digitalcommons.unl.edu/psychfacpub/1006

This Article is brought to you for free and open access by the Psychology, Department of at DigitalCommons@University of Nebraska - Lincoln. It has been accepted for inclusion in Faculty Publications, Department of Psychology by an authorized administrator of DigitalCommons@University of Nebraska - Lincoln. 


\title{
Attributions of Blame in a Hypothetical Child Sexual Abuse Case: Roles of Behavior Problems and Frequency of Abuse
}

\author{
Kate Theimer, MA \& David J. Hansen, PhD \\ University of Nebraska-Lincoln \\ Corresponding author - Kate Theimer, Department of Psychology, \\ University of Nebraska-Lincoln, 238 Burnett Hall, Lincoln, NE 68588-0308, USA. \\ email KateTheimer4@gmail.com
}

\begin{abstract}
Youth who are blamed for their sexual abuse may experience increased negative outcomes, such as amplified self-blame. Similarly, blaming nonoffending parents can impede their ability to support their child following disclosure. Understanding the factors that influence how people perceive victim, caregiver, and perpetrator responsibility is imperative for the protection and treatment of families who have experienced sexual abuse. Little research has explored victim and abuse characteristics that influence the perception of sexual abuse. As such, the purpose of this study was to examine the roles of behavior problems and frequency of abuse in the attribution of blame in a hypothetical sexual abuse case. In addition, the relationship between several respondent characteristics and assignment of responsibility were explored as secondary aims. The study used a two (behavior problems: three suspensions in one school semester vs. no mention of behavior problems) by two (one abuse occurrence vs. five abuse occurrences) between-subjects design. Seven hundred forty-two participants read one of the four child sexual abuse (CSA) vignettes and completed measures related to responsibility. ANOVAs revealed those who read
\end{abstract}

Published in Journal of Interpersonal Violence 35:11-12 (2020), pp 2142-2163.

DOI: $10.1177 / 0886260517716943$

Copyright (C) 2017 Kate Theimer \& David J. Hansen. Published by SAGE Publications. Used

by permission. 
a vignette where the youth experienced multiple abuse incidents rated the victim as more responsible regardless of whether or not the youth was described as having behavior problems. Results indicate that respondents may have attributed more blame to the victim due to the belief that she could have done something to stop the abuse after the first incident. The abuse frequency manipulation when combined with the behavior manipulation appeared to relate to how respondents perceived the victim's parents. Males and younger respondents attributed more blame to the victim; however, sexual abuse or assault history did not associate with victim responsibility ratings. Clinical and research implications were discussed.

Keywords: attributions, blame, child sexual abuse, behavior problems, abuse frequency

Child sexual abuse (CSA) is thought to be one of the nation's most serious concerns, affecting youth of all genders, ages, ethnicities, and backgrounds (U.S. Department of Health and Human Services, 2015). CSA is associated with both short and long term negative consequences, including depression, suicide, posttraumatic stress disorder (PTSD), inappropriate or risky sexual behavior, low self-esteem, substance use, and anti-social behavior (Maniglio, 2009; Tyler, 2002). Multiple factors have been associated with victim outcomes, including the victim's attribution of blame (Celano, Hazzard, Campbell, \& Lang, 2002; Valle \& Silovsky, 2002). Those who experience sexual abuse frequently try to understand why the abuse occurred and, in this process, victims can make internal (blaming the self) and external (blaming the perpetrator, the situation) attributions for the abuse (Feiring, Taska, \& Chen, 2002). Youth who exhibit more internal attributions tend to have worse outcomes such as greater depression, avoidance, intrusive thoughts, hyperarousal, future revictimization, and lower self-esteem (Feiring et al., 2002).

Although much research has been done on victim self-blame and the associated negative outcomes, less research has focused on other people's perceptions of victim responsibility. It is important to study societal attitudes of CSA, specifically victim responsibility, because of the associated negative outcomes for the victim. First, other people's attributions of blame toward the victim may lead the victim to selfblame. One study found that youth blamed by others are likely to internalize responsibility and come to believe they are at fault (Hunter, Goodwin, \& Wilson, 1992). This can set up a cycle of abuse for these individuals, as they may believe they are deserving of abuse (Back \& 
Lips, 1998). Another study found that children whose mothers blamed them for their sexual abuse had increased self-blame (Hazzard, Celano, Gould, Lawry, \& Webb, 1995). More comprehensive research with adult rape survivors shows a relationship between others' perceptions of blame and victim self-blame (e.g., Randall, 2010). Specifically, Campbell, Dworkin, and Cabral (2009) found that being blamed by others exacerbates self-blame and is associated with increased symptoms of PTSD.

Second, because disclosures frequently result in victim blaming (Feiring et al., 2002; Ullman, 2003) victims may fear or avoid disclosure. Concealment of sexual abuse has been associated with negative psychological and physical consequences, in part, because delayed disclosure may inhibit access to mental health services (GoodmanBrown, Edelstein, Goodman, Jones, \& Gordon, 2003). Ruggiero et al. (2003) found children who delay disclosure by one month or more were more likely to develop PTSD and depression. Another study found that $44 \%$ of those who did not immediately report were subsequently abused by the same perpetrator (Sas, Cunningham, Hurley, Dick, \& Farnsworth, 1995). Delaying disclosure may also weaken the child's credibility if he or she discloses later (Goodman-Brown et al., 2003). Overall, youth may be afraid to disclose their sexual abuse for fear of judgment or blame from others, resulting in delayed disclose. Consequently, youth may experience even more judgment and blame for not immediately disclosing.

Third, the perception from parents and others that the victim should be held responsible may impact supports available to the victim. For example, family and friends may be less likely to provide compassion and care, such as taking the victim to therapeutic services, if they believe the youth is blameworthy. Parental support following disclosure has consistently been linked to better child adjustment (Cohen \& Mannarino, 2000). This support includes believing and emotionally supporting the child, keeping the child safe, and never blaming the child (Cohen \& Mannarino, 2000). On a broader societal level, Rogers, Josey, and Davies (2007) found that children cannot be fully supported until the general population is educated and no longer endorse CSA myths (Collings, 1997), including the idea that blame can be diffused to the victim.

Finally, when the victim receives blame for the sexual abuse, the perpetrator may not receive proper treatment or punishment for his 
or her actions. This may reinforce the perpetrator's behavior, increasing the likelihood of recidivism (Back \& Lips, 1998). Holding victims responsible rather than perpetrators may lead to a climate conducive to sexual abuse (Waterman \& FossGoodman, 1984).

Just as inappropriately attributing responsibility to the victim can lead to negative outcomes, ascribing blame to the victim's nonoffending parents can also be harmful. Following the disclosure of CSA, parents often feel a sense of blame and guilt because they feel as though they failed to protect their child (Hébert, Daigneault, Collin-Vézina, \& Cyr, 2007; van Toledo \& Seymour, 2013) and being blamed by others could intensify these feelings. Receiving blame from others also impedes parents' ability to support their child following CSA disclosure (Hébert et al., 2007).

To study attribution of blame, researchers most commonly have participants read a vignette depicting a hypothetical sexual abuse case and then complete a questionnaire on who they believe is responsible for the abuse (e.g., victim, perpetrator, nonoffending parents). Studies consistently show that respondents place more blame on older compared with younger victims (e.g., Back \& Lips, 1998; Rogers \& Davies, 2007; Rogers et al., 2007) and that male respondents attribute more responsibility to victims compared with female respondents (e.g., Broussard \& Wagner, 1988; Davies \& Rogers, 2009; Esnard \& Dumas, 2013; Graham, Rogers, \& Davies, 2007; Rogers, Lowe, \& Boardman, 2014; Rogers, Titterington, \& Davies, 2009). In addition, some studies have found that respondents with a history of CSA ascribe less blame to victims compared with respondents who have not experienced CSA (Ford, Schindler, \& Medway, 2001; Waterman \& FossGoodman, 1984) while other studies have shown no difference in assignment of blame between participants with a CSA history and those without (Harding, Zinzow, Burns, \& Jackson, 2010; Ko \& Koh, 2007; Rogers \& Davies, 2007). To our knowledge, no studies have examined the relationship between respondent age and ratings of victim blame.

Variables targeting how the victim immediately reacts to the sexually abusive encounter have also been widely studied but suggest mixed findings. These studies typically describe the victim as either encouraging, passive, or resistant during the encounter. Victims described as encouraging the encounter are consistently deemed more culpable by respondents (Broussard \& Wagner, 1988; Ford et al., 2001). Broussard and Wagner (1988) additionally found that children 
who were passive were held more responsible than those described as resistant. However, Rogers et al. (2009) found no difference in level of blame assigned to victims who actively resisted the abuse compared with those who did not.

Studies exploring CSA and perceptions of responsibility typically use a female victim character in the hypothetical vignette. Thus, less research has investigated the relationship between victim gender and blame. Back and Lips (1998) found no difference in respondents' assignment of blame toward male versus female victims. However, Esnard and Dumas (2013) found that male respondents blamed the victim more when the victim was a boy. Although these findings are mixed within the CSA research, the adult sexual assault literature shows that male victims generally are assigned more blame because they are believed to be more capable of physically defending themselves against sexual assault (Davies \& Rogers, 2006).

Regarding perceptions of nonoffending parents, research has shown that respondents ascribe more responsibility to caregivers when the victim is younger (Back \& Lips, 1998; Rogers et al., 2007). Back and Lips (1998) hypothesized that "the closer to adulthood a child becomes, the more responsible the child and the less responsible the non-offending parents" (p. 1246). However, Waterman and Foss-Goodman (1984) found no difference in parent blame based on victim age. In addition, studies have found that male respondents attribute more responsibility to nonoffending parents compared with female respondents (e.g., Back \& Lips, 1998; Graham et al., 2007).

Concerning the literature on perpetrator responsibility, studies show that, compared with female participants, male respondents tend to blame the perpetrator less (Esnard \& Dumas, 2013; Rogers \& Davies, 2007). This was especially true when the perpetrator was a female and the victim was a male (Esnard \& Dumas, 2013). Overall, female perpetrators tend to be rated less negatively than male perpetrators (Broussard \& Wagner, 1988; Maynard \& Wiederman, 1997; Rogers \& Davies, 2007). When examining victim behaviors, Rogers et al. (2009) found that perpetrators were blamed more when the victim physically resisted compared with verbally resisted.

Currently there is a gap in research efforts examining clinically relevant, nondemographic victim variables, such as victim trait variables and abuse related variables that may associate with attributing blame to the victim, nonoffending caregivers, and perpetrator. Two 
variables that have received less attention are behavior problems and abuse frequency (e.g., single vs. multiple occurrences), which will be further explored below.

\section{Behavior Problems}

Although the experience of CSA is related to an increase in externalizing behaviors (Tyler, 2002), problematic behaviors (e.g., delinquency) have also been associated with increased risk for victimization (Cuevas, Finkelhor, Turner, \& Ormrod, 2007). Based on extensive clinical experience of the investigators working with victims of CSA, youth who present to treatment with existing behavior problems also tend to report feeling blamed by others. However, to our knowledge, no studies have explored the relationship between a youth's prior behavior problems and receiving blame for the experience of sexual abuse. There are many potential reasons as to why youth exhibiting problematic behaviors may be more likely to be blamed. Anecdotally, in many clinical cases of CSA seen by the investigators, a victim's caregivers or other support systems may question whether the actions of the delinquent youth (e.g., sneaking out of the house, using substances) corresponded with the abusive experience. This shifts the blame away from the perpetrator and onto the victim. Commonly cited in the victim blaming literature, Lerner's (1980) just world theory finds that people have a proclivity to view the world as inherently fair with no victim completely innocent. Thus, it is believed that a person must have done something or have a characterological defect to warrant victimization. Research shows that those with stronger just world beliefs tend to perceive sexual abuse victims as more culpable (Broussard \& Wagner, 1988). Therefore, it is reasonable to postulate that a victim described as having behavior problems may be more likely to be blamed because the youth may be viewed as having contributed to the abuse or viewed as lacking innocence.

Shaver's (1970) defensive attribution theory also attempts to explain why people assign responsibility to victims and provides support for the hypothesis that victims described as delinquent may be more likely to be blamed. This theory posits that people will ascribe less blame to victims when they perceive themselves as similar and 
more blame to victims if they perceive themselves as dissimilar. Attributing blame to the victim is described as a coping mechanism that protects the self from receiving responsibility in a similar future situation (Shaver, 1970). This allows people to believe that they are inherently different than the victim and protects them from believing they are vulnerable to victimization (Shaver, 1970).

Delinquent behavior is most commonly associated with adolescence both in the media and professional literature (Arnett, 2000) and research shows that older youth are more likely to be blamed for CSA (e.g., Rogers \& Davies, 2007). Adolescents, compared with younger children, are thought to be less sexually naïve and have a greater risk of being perceived as encouraging the encounter (Davies \& Rogers, 2009). Adolescents are also perceived as being more able to physically resist sexual abuse and more able to verbally communicate their abuse through a disclosure compared with younger children (Maynard \& Wiederman, 1997). Therefore, older youth who present with problematic behavior may be particularly likely to be blamed.

There is no available research targeting how others attribute blame toward parents of CSA victims who present with behavior problems or how this might affect perpetrator blame. However, there is evidence to show that people tend to perceive parents of delinquent youth as responsible for their child's problematic behavior (Hoeve et al., 2008). In addition, research shows that parenting behaviors and aspects of the family environment can influence youth's problematic behavior (e.g., Hoeve et al., 2008), indicating that people may perceive the family to be responsible for the youth's behavior and potentially their abuse experience.

\section{Abuse Frequency}

One study found that a victim's abuse history did not associate with respondents' ratings of victim culpability (Rogers et al., 2007). For example, in this study, there was no difference in blame assigned to a victim described as having one sexual abuse occurrence compared with a victim described as having more than one abuse occurrence either by the same perpetrator or by several different perpetrators. However, abuse history did generally relate to perpetrator blame 
(Rogers et al., 2007). The study found that female respondents rated the perpetrator who offended against the victim once as more responsible compared with a perpetrator who repeatedly offended against the victim. These findings show that abuse frequency and repeated victimization broadly associates with how respondents perceive the sexual abuse, particularly how participants view the perpetrator. Although more research is still needed in the child literature, within the adult sexual assault literature, it is believed that repeated victimization is associated with increased blame from others (Campbell et al., 2009; Grauerholz, 2000). No studies have examined the role of abuse frequency on perceptions of parent blame. It is possible that people will judge parents whose child was abused over several time points more harshly because they may perceive these parents to have lacked sufficient supervision and monitoring of their child.

\section{Study Aims and Hypotheses}

Understanding the factors that influence why or when people choose to blame the victim, caregiver, and perpetrator is imperative for the protection and treatment of youth and families who experience sexual abuse. As such, the purpose of this study was to examine the roles of behavior problems and frequency of abuse on the attribution of blame in a hypothetical CSA case. It was hypothesized that respondents who read a vignette where the youth is described as having behavior problems and having more than one abuse occurrence would assign the most blame to the victim. Similarly, it was hypothesized that respondents who read a vignette where the youth is described as having behavior problems and having more than one abuse occurrence would also assign the most blame to the nonoffending caregiver. Given the paucity of prior research, no research hypotheses were formed concerning perceptions of perpetrator blame or perceptions that the youth could have prevented the abuse. Consistent with the literature, the relationship between several respondent characteristics and assignment of responsibility were also examined as additional independent variables, including respondent gender, age, and abuse history. 


\section{Method}

Design

The study used a two (behavior problems: three suspensions in one school semester vs. no mention of behavior problems) by two (one abuse occurrence vs. five abuse occurrences) between-subjects design. Dependent variables were several questions relating to victim, perpetrator, and parent responsibility as well as whether the victim could have prevented the abuse. Respondents were randomly assigned to one of four conditions.

\section{Participants}

Participants were 742 undergraduates at a Midwestern university who were recruited through the psychology department's research participation website. Students were 19 to 55 years old $(M=20.4, S D$ $=2.6$ ) and $74.3 \%$ female. Of the sample, 78.7\% identified themselves as European American, 6.6\% as Asian, 5.4\% as Latino or Hispanic, $4 \%$ as biracial, $3.4 \%$ as African American, .5\% as multiracial, .4\% as Native American, and .9\% did not identify with any of the above ethnicities. The majority of participants were in their second (33.6\%) or third (29.4\%) year in college, $16.3 \%$ were in their fourth year, $14.8 \%$ were in their first year, 5.5\% were in their fifth or more year, and .4\% did not disclose their year in college. Of the sample, $28.8 \%$ answered their parents' (family) income as over $\$ 100,000$ per year, $20.6 \%$ as between $\$ 81$, oo and $\$ 99,000,17.5 \%$ as between $\$ 61$,ooo and 80,000, $14.6 \%$ as between $\$ 41$, ooo and $\$ 60,000,12.3 \%$ as between $\$ 21$,000 and $\$ 40,000,5.3 \%$ as $\$ 20,000$ or below, and .9\% chose not to disclose their family's income. The majority of students were single $(82.1 \%)$, heterosexual (95.6\%), Christian (72.9\%), and did not have any children (93.1\%). Using chi-square analyses, the four conditions did not significantly differ $(p>.05)$ in any demographic variable.

Materials and Measures

Participants received an online "digital packet" containing a consent form, instructions, one of the four CSA vignettes, the measures 
described below, and a debriefing form. Participants read the CSA vignettes and then completed the measures in the order listed below.

CSA vignettes. Four vignettes were used to describe the two-by-two variable manipulations (see Appendix). Vignettes outlined a hypothetical CSA case in which a 15-year-old female named Talia was sexually abused by a 35-year-old male neighbor named Asher. Character names were chosen based on their moderate popularity among several ethnic backgrounds. Gender of the victim was chosen because statistics show that more females are sexually abused than males (American Psychological Association [APA], 2014). Gender of the perpetrator was chosen because more males are perpetrators of CSA, especially when the victim is female (APA, 2014). Victim-perpetrator relationship and ages were chosen based on previous vignette studies (Back \& Lips, 1998; Rogers et al., 2007; Rogers et al., 2009; Waterman \& Foss-Goodman, 1984) as well as current statistics outlining that the majority of CSA offenders are known acquaintances to the victim and that children aged 12 years and older are most at risk for CSA (APA, 2014). Vignette length and general format were determined based on previous CSA vignette studies (Back \& Lips, 1998; Esnard \& Dumas, 2013; Rogers et al., 2007). A team of four doctoral students with experience working with CSA victims and families carefully reviewed the hypothetical vignettes and gave feedback to make the vignettes as clear and realistic as possible.

Attribution questions. Four attribution questions assessed how responsible participants believe the victim, victim's parents, and perpetrator are for the abuse occurring. These questions were created for this study and were based on a previous similar study (Harding et al., 2010). These questions were rated on a 4-point Likert-type scale in which $1=$ not at all responsible and $4=$ completely responsible. A final question assessed participants' belief that the victim could have done something to prevent or avoid the abuse. This question was rated on a 6 -point Likert-type scale in which $1=$ disagree strongly and $6=$ agree strongly. Given the unit of analysis was each individual item, no analyses for internal consistency were run.

CSA history questionnaire. This two-item questionnaire was created for the purpose of this study and measured respondents' own 
history of sexual abuse and sexual assault. The two questions "Have you experienced sexual abuse as a child or adolescent?" and "Have you experienced sexual assault as an adult?” were answered in a yes or no format.

Demographic questionnaire. Participants responded to a variety of demographic questions, including age, gender, ethnicity, year in college, family income, relationship status, sexual orientation, number of children, and religious affiliation.

\section{Procedure}

Participants were recruited through the university's psychology department research participation website. Students enrolled in at least one psychology course can view research studies and choose in which studies they would like to participate through this website. Once students chose to participate, they were immediately linked to the online study. Participants were instructed that the study would last a maximum of one hour and they would subsequently receive two research participation credits for their completion of the study. All procedures were approved by the University's Institutional Review Board. Exclusion criteria were based on an online vignette study done by Brank and Wylie (2014). The original sample size of the current study included 818 students. Participants were excluded from the study if they took less than $5 \min (n=36)$ or more than $60 \min (n=28)$ to complete the study.

Those who were excluded for taking too long were "presumed to have left the study while in progress and were not sensitive to the manipulations" (Brank \& Wylie, 2014, p. 8). Students were also excluded if they only answered the first several questions of the study and did not attempt to complete the study $(n=12)$. After exclusions, the final sample was 742 participants.

\section{Results}

Victim/Abuse Characteristics and Responsibility Ratings

A $2 \times 2$ ANOVA examined the effect of victim behavior problems and abuse frequency on ascription of responsibility to the victim, parent, 
Table 1. Summary of Victim, Parent, and Perpetrator Responsibility Ratings and Prevention Ratings.

\begin{tabular}{|c|c|c|c|c|c|c|c|}
\hline & & & $\begin{array}{l}\text { Behavior } \\
\text { oblems }\end{array}$ & & & $\begin{array}{l}\text { avior } \\
\text { blems }\end{array}$ & \\
\hline & & $M$ & $S D$ & $n$ & $M$ & $S D$ & $n$ \\
\hline Victim & One Abuse Incident & 1.36 & 0.565 & 183 & 1.26 & 0.496 & 184 \\
\hline Responsibility & Multiple Abuse Incidents & 1.59 & 0.600 & 191 & 1.59 & 0.695 & 184 \\
\hline Parent & One Abuse Incident & 1.39 & 0.635 & 183 & 1.41 & 0.612 & 184 \\
\hline Responsibility & Multiple Abuse Incidents & 1.49 & 0.687 & 191 & 1.61 & 0.746 & 184 \\
\hline Perpetrator & One Abuse Incident & 3.92 & 0.322 & 183 & 3.92 & 0.345 & 184 \\
\hline Responsibility & Multiple Abuse Incidents & 3.86 & 0.494 & 191 & 3.84 & 0.504 & 184 \\
\hline Victim & One Abuse Incident & 3.74 & 1.373 & 183 & 3.66 & 1.308 & 184 \\
\hline Prevention & Multiple Abuse Incidents & 4.18 & 1.318 & 191 & $4 \cdot 34$ & 1.312 & 183 \\
\hline
\end{tabular}

and perpetrator. Table 1 presents the means and standard deviations for each condition. Results showed significant mean differences in victim responsibility ratings among the four conditions, $F(3,738)=$ 14.87, $M s e=.35, p<$.001. Pairwise comparisons using Least Significant Difference ((LSD) with a minimum mean difference $=.12$ ) revealed that those who read a vignette where the youth experienced multiple abuse occurrences rated the victim as more responsible regardless of whether or not the youth was described as having behavior problems. In other words, ratings of responsibility were significantly higher for the conditions that included multiple abuse incidents and, among the conditions that described multiple abuse incidents, there was no difference in ratings between the condition with the description of behavior problems and the condition with no mention of behavior problems. These results were inconsistent with our hypothesis that respondents who read a vignette where the youth is described as having behavior problems and having more than one abuse occurrence would assign the most blame to the victim.

Results also showed significant mean differences in parent responsibility ratings among the four conditions, $F(3,738)=4.00, M s e=.45$, $p=$.0o8. Pairwise comparisons using LSD (with a minimum mean difference $=.13$ ) revealed that those who read a vignette where the youth experienced multiple abuse occurrences and was described as 
having behavior problems rated the parents as more responsible compared with those who read a vignette where the youth was described as having one abuse incident regardless of whether or not the youth was described as having behavior problems. The abuse frequency manipulation when combined with the behavior manipulation appeared to relate to how respondents perceived the victim's parents. However, the condition with no mention of behavior problems and multiple abuse occurrences did not significantly differ from any of the other conditions, making the results inconsistent with our hypothesis.

There was no difference among the conditions in ratings of perpetrator responsibility, $F(3,738)=1.65, M s e=.18, p>.05$. No hypotheses on ratings of perpetrator blame were created. Results indicated that respondents generally assigned higher levels of blame to the perpetrator compared with the victim or the nonoffending caregivers across the conditions.

Results showed significant mean differences in victim prevention ratings among the four conditions, $F(3,737)=11.44$, Mse $=1.763, p<$ .001. Pairwise comparisons using LSD (with a minimum mean difference $=.27$ ) revealed that those who read a vignette where the youth experienced multiple abuse occurrences rated the victim as significantly more able to prevent her abuse regardless of whether or not the youth was described as having behavior problems. The pattern of results among the conditions for the victim prevention question was the same as the pattern of results for the victim responsibility question above.

\section{Participant Gender and Responsibility Ratings}

A one-way ANOVA examined the effect of respondent gender on ascription of responsibility to the victim, parents, and perpetrator. Male participants rated the victim as significantly more responsible, $F(1$, $738)=17.50$, Mse $=.364, p<.001$, the parents as significantly more responsible, $F(1,738)=30.88$, Mse $=.438, p<.001$, and the perpetrator as significantly less responsible, $F(1,738)=11.24$, Mse $=.178$, $p=.001$, compared with female participants. Male participants also rated the victim as significantly more able to prevent or avoid her abuse, $F(1,737)=17.90$, $M s e=1.80, p<.001$. 
Participant Sexual Abuse and Assault History and Responsibility Ratings

Of the sample, 79 (10.6\%) participants had experienced sexual abuse. Within this group, $70(88.6 \%)$ were female. Similarly, 79 (10.6\%) had experienced sexual assault as an adult; 76 (96.2\%) of these participants were female.

One-way ANOVAs examined the effect of respondent abuse/assault history on ascription of responsibility to the victim, parent, and perpetrator. There were no significant differences in victim responsibility, parent responsibility, perpetrator responsibility, and prevention ratings between those who experienced sexual abuse as a youth and those who did not (all $p>$.05). Similarly, there were no significant differences in responsibility ratings between those who experienced sexual assault as an adult and those who did not (all $p>.05$ ).

Participant Age and Responsibility Ratings

Pearson's correlation between respondent's age $(M=20.38, S D=$ 2.61) and victim responsibility rating $(M=1.45, S D=.61)$ was $r(740)$ $=-.082, p=.026$. Age was negatively associated with victim responsibility ratings such that younger participants rated the victim as more responsible. Participants' age was not related to parent responsibility, perpetrator responsibility, and prevention rating (all $p<.05$ ).

\section{Discussion}

\section{Victim/Abuse Characteristics and Responsibility Ratings}

It was hypothesized that respondents who read a vignette where the 15-yearold victim was described as having behavior problems and having more than one abuse occurrence would assign the most blame to the victim. Contrary to this hypothesis, the behavior problems manipulation did not appear to relate to the assignment of responsibility to the victim. Rather, the abuse frequency manipulation appeared to largely relate to respondents' attribution of blame. This pattern of findings on victim responsibility ratings was similar to the study's 
findings on participants' beliefs that the victim could have prevented or avoided her abuse.

Higher responsibility and prevention ratings for multiple abuse occurrences may be due to the belief that more onus should be placed on the victim because she did not make an effort to stop the sexual abuse after the first incident. This may be particularly true given that older youth are perceived as more able to physically resist sexual abuse and more able to verbally communicate their abuse through a disclosure compared with younger children (Maynard \& Wiederman, 1997). Research in the adult sexual assault literature goes further, hypothesizing that if the victim had multiple abuse occurrences, people may perceive that she wanted the sexual encounters and thus deserved the abuse (e.g., Randall, 2010).

In addition, the findings that participants tended to ascribe more responsibility to the victim who experienced five abuse occurrences may also reflect a lack of knowledge about the grooming process perpetrators often use to manipulate their victims (see Craven, Brown, \& Gilchrist, 2006 for a review). Grooming usually begins with an offender developing a relationship with a youth and gaining his or her trust as well as the caregivers' trust. Perpetrators often make children feel special by giving them gifts, special privileges, or attention and may find opportunities to be alone with the youth. Offenders typically progress from affectionate nonsexual touches (e.g., hugging) to sexual touches. After the sexual abuse incident(s), perpetrators often threaten to hurt the youth or their family if they tell someone or tell them no one will believe them. Many of these behaviors are exemplified in the case vignettes provided. Caregivers and others who are not aware of the grooming process may have difficulty understanding why children do not disclose the sexual abuse immediately following the incident. This is particularly relevant given that most youth do not disclose immediately and some never disclose (Berliner, 2011). In contrast with these potential explanations, a prior study found that abuse frequency did not relate to respondents' ascription of responsibility (Rogers et al., 2007); as such, more research is needed to understand exactly how abuse frequency relates to victim culpability.

The behavior manipulation when combined with the abuse frequency manipulation related to how respondents perceived the victim's parents. Results suggest that respondents may have attributed 
more blame to the victim's parents if they believed the parents could have monitored the adolescent's activities more closely over several time points, particularly for a youth with identified behavior problems. Past research has shown that nonoffending mothers often receive blame from others due to the perception that she must have been negligent for the abuse to occur (e.g., Leonard, 2013). These perceptions rely on unrealistic expectations of parents being able to sense abuse and then stop it. Furthermore, these beliefs fail to recognize the tactics offenders use to gain parents' trust, to keep children from disclosing to their parents, and to conceal the abuse from victim's families. How offenders manipulate a victim's family is exemplified in the vignette as the victim's parents were described as having invited the to-be perpetrator over to their house several times prior to the sexual abuse, showing that the parents likely trusted the adult around their child.

Similarly, in line with the defensive attribution theory (Shaver, 1970), participants may have believed they would have somehow done something differently if they were the victim's caregivers, thus ascribing more responsibility to the parents. Unfortunately, parents and caregivers often feel a sense of blame or guilt following the disclosure of CSA (van Toledo \& Seymour, 2013) and receiving blame from others could intensify their feelings of self-blame and guilt. Receiving blame from others also impedes parents' ability to support their children following CSA disclosure (Hébert et al., 2007). Placing the onus on the victim's parents shifts the focus away from appropriately perceiving the perpetrator as solely responsible for the abuse.

There was no difference among the conditions in ratings of perpetrator responsibility. Rogers et al. (2007) found that female respondents rated the perpetrator who offended against the victim once as more responsible compared with a perpetrator who repeatedly offended against the victim. Past research is mixed as to whether victim age associates with perpetrator responsibility (Rogers \& Davies, 2007; Rogers et al., 2007). In addition, some studies do not ask participants about their perceptions of perpetrator responsibility (e.g., Back \& Lips, 1998). More research is needed to understand offender culpability. 


\section{Participant Gender and Responsibility Ratings}

Male participants rated the victim as more responsible, the parents as more responsible, and the perpetrator as less responsible compared with females. Male respondents also rated the victim as significantly more able to prevent or avoid her abuse. These findings are consistent with past research which overwhelmingly shows that male participants attribute more responsibility to victims compared with females (e.g., Rogers et al., 2014). This pattern could be explained by Shaver's (1970) defensive attribution theory that states people will ascribe less blame to victims when they perceive themselves as similar and more blame to victims if they perceive themselves as dissimilar. In addition to the gender difference with the adolescent in the vignette, male participants were less likely to have experienced sexual abuse. As such, males may identify less with the victim and rate her as more responsible.

\section{Participant Sexual Abuse and Assault History and Responsibility} Ratings

Respondents' sexual abuse and sexual assault history did not associate with ratings of victim, parent, or perpetrator responsibility. Although no formal hypotheses were formed, this variable was explored to examine whether respondents with a sexual abuse or assault history were less likely to rate the victim as responsible because they view themselves as similar to the victim, consistent with the defensive attribution theory (Shaver, 1970). Past research shows mixed findings. Several studies have found that respondents with a history of CSA ascribe less blame to victims compared with respondents who have not experienced CSA (Ford et al., 2001; Waterman \& Foss-Goodman, 1984). However, similar to the results of the current study, other studies have shown no difference in assignment of blame between participants with a CSA history and those without (Harding et al., 2010; Ko \& Koh, 2007; Rogers \& Davies, 2007). More research is needed to understand this relationship. 


\section{Participant Age and Responsibility Ratings}

Interestingly, younger participants rated the victim as more responsible. However, participants' age was not related to parent responsibility, perpetrator responsibility, and prevention rating. To our knowledge, no prior studies have examined respondent age as a predictor of victim responsibility likely because most studies use adult populations (e.g., college students) where respondents may not significantly differ in age or development. Our sample was also largely homogeneous, with 93\% of participants aged between 19 and 22 years and few participants $(n=10)$ aged 30 years or older. It is possible that older students, perhaps with greater exposure to the field of psychology or increased knowledge about sexual abuse and assault, may be more informed about appropriately attributing blame. However, this is conjecture and further research is needed to understand this relationship.

\section{Clinical and Policy Implications}

Given that victims may experience blame from others, it is imperative that treatments for CSA assess and address youth's feelings of blame. Based on the results of this study, this is particularly relevant as it is common for victims to experience multiple abuse occurrences before disclosure (Berliner, 2011). Because blame from others is associated with an individual's own self-blame (e.g., Hunter et al., 1992), it is important that treatment providers also assess and address youth's self-blame. In addition, it is necessary to address these issues with family members to help them cope and appropriately attribute blame. Fortunately, CSA interventions commonly include the youth's nonoffending caregivers.

On a larger scale, more efforts are needed to educate the public about CSA blame. Considering longer abuse frequency is related to higher levels of self-blame and increased negative outcomes for victims, it is imperative that the general public (including caregivers and friends of victims, law enforcement who work with victims, and professionals who work with victims) clearly understand that youth should not be deemed more culpable due to the length of their abuse or delayed disclosure. Instead, to better support and protect victims, people should be educated on how their reactions or perceptions may affect victims. 


\section{Limitations and Suggestions for Future Research}

Although the study adds to the current literature on the perceptions of CSA responsibility, there were several limitations. Participants were students at a university, primarily between the ages of 19 and 22 years. Therefore, the results may not generalize across all populations or settings. College educated participants who are enrolled in a psychology course may have more knowledge about the victim blaming literature compared with a community sample. In addition, the sample was overwhelmingly European American, middle-class, heterosexual, and Christian and the majority of respondents were single with no children. All of these demographic variables (which affect learning experiences, exposure to life events, etc.) could have impacted participants' responses in this study. To improve the diversity of the sample, the study could be replicated using a national online sample to better represent the general population and incorporate a wider range of beliefs and perceptions.

This study examined CSA using a 15-year-old female victim and a male perpetrator described as the victim's neighbor. Therefore, results may not generalize to other sexual abuse cases such as intrafamilial abuse, abuse of males, abuse with female perpetrators, abuse from a stranger, or sexual abuse of young children. As described above, the vignette exemplified the grooming process some perpetrators use to manipulate victims and their families and thus may not generalize to abuse cases where grooming behaviors are not present. Future research could explore whether respondents assign differing levels of blame to the victim, parent, and perpetrator depending on the perpetrator's relationship to the victim.

Although this study was the first to explore how behavior problems could relate to ascription of responsibility, it is possible that the behavior problems manipulation was not strong enough. Future research using a vignette design could describe the youth as having more extreme behavior problems, such as physical aggression toward others or an arrest history. The vignette could also more specifically describe the youth as having a behavior disorder such as Oppositional Defiant Disorder or Conduct Disorder. In a replication, research could also incorporate manipulation tests to ensure the participants are attending to the vignette manipulation. 
The participants were asked whether or not they had experienced a sexually abusive experience as a youth or adult to determine whether this experience associated with responsibility ratings. Collecting more information on the nature of the abusive experiences of the participants (e.g., type of sexual abuse, relationship to the perpetrator) could have added to the findings. Future research in this area could assess these factors more comprehensively.

\section{Conclusion}

In conclusion, while much research has examined victim self-blame and the associated negative outcomes, less research has focused on others' perceptions of victim responsibility. How other people attribute blame to the victim cannot be overlooked due to the possible negative outcomes for the victim. The purpose of this study was to examine the roles of behavior problems and frequency of abuse in the attribution of blame in a hypothetical CSA case. Results found those who read a vignette where the youth experienced multiple abuse incidents rated the victim as more responsible regardless of whether or not the youth was described as having behavior problems. Results indicate that respondents may have attributed more blame to the victim due to the belief that she could have done something to stop the abuse after the first incident. The abuse frequency manipulation when combined with the behavior manipulation appeared to relate to how respondents perceived the victim's parents. Males and younger respondents attributed more blame to the victim; however, sexual abuse or assault history did not associate with victim responsibility ratings. This study adds to the literature by examining understudied factors that may influence perceptions of responsibility and provided implications for clinical practice and directions for future research.

\section{Appendix}

\section{Child Sexual Abuse (CSA) Vignettes}

The following vignette shows the behavior manipulation as well as the multiple abuse occurrences manipulation. The sentence, "She has 
a history of behavioral problems at school and at home. This school year she has been suspended three times for behavioral misconduct and serious disruption to the classroom," was not included in the vignettes with no mention of behavior problems. The portion describing the four additional abuse experiences was not included in the vignettes where the adolescent was described as experiencing abuse once. All vignettes ended with the adolescent walking home, telling her parents, and the authorities being contacted.

Talia is a 15-year-old girl who attends Clovecrest High School.

She has a history of behavioral problems at school and at home. This school year she has been suspended three times for behavioral misconduct and serious disruption to the classroom.

While walking home from school one afternoon in late January, her 35-year-old neighbor, Asher, invited her inside for some hot chocolate and to play videos games. Talia's family first met Asher about 5 months ago at the back-to-school neighborhood block party and had since invited him over to dinner several times. She figured going to his house would be okay. Once inside, he offered her hot chocolate and the two began playing video games. Talia noticed Asher sitting closer and closer to her as they played the game. He told her that he thought she was beautiful. While his actions made her feel a little uncomfortable, she thought that he was just being friendly and ignored this feeling. At the end of their third game, he set down his controller and asked whether she wanted to play a different game. He then slid his hand up her leg and fondled her genitals. She was incredibly shocked and did not know how to respond. He then unzipped his pants and made her perform oral sex on him. Once he was finished he told her to never tell anyone and that this would be their little secret. As she walked home she was confused at what had just happened.

The next weekend Asher approached her outside while she was grabbing the mail. He was very friendly with her and he asked her if she wanted to come inside to share a pizza he just ordered. Although reluctant, she followed him inside where they shared pizza and a soda. After they cleaned up, he led her to the couch where he again fondled her genitals and made her perform oral sex on him. He again instructed her to not tell anyone.

Asher continued to invite Talia to his house for the following three weekends where he fondled her and made her perform oral sex. On 
that last weekend after walking home from Asher's house, she told her parents what Asher had done and the authorities were contacted.

Acknowledgments - The authors would like to thank Alayna Schreier and the graduate students of the Child Maltreatment Lab for their efforts on this study.

Conflicting Interests - The authors declared no potential conflicts of interest with respect to the research, authorship, and/or publication of this article.

Funding - The authors received no financial support for the research, authorship, and/or publication of this article.

\section{Author Biographies}

Kate Theimer, MA, is a doctoral student in the Clinical Psychology Training Program at the University of Nebraska-Lincoln. Her research interests include the assessment and intervention of child maltreatment, the correlates and outcomes of child maltreatment, and the factors of maltreatment that influence attributions of responsibility.

David J. Hansen, PhD, is professor of psychology, director of the Clinical Psychology Training Program, and Director of the Center for Brain, Biology and Behavior at the University of Nebraska-Lincoln. His primary research area is child maltreatment (sexual abuse, physical abuse, and neglect), including assessment and intervention with victims and families, maltreatment prevention, and the correlates and consequences of maltreatment.

\section{References}

American Psychological Association. (2014). Child sexual abuse: What parents should know. Retrieved from http://www.apa.org/pi/families/resources/childsexual-abuse.aspx

Arnett, J. (2000). Emerging adulthood: A theory of development from the late teens through the twenties. American Psychologist, 55, 469-480.

Back, S., \& Lips, H. M. (1998). Child sexual abuse: Victim age, victim gender, and observer gender as factors contributing to attributions of responsibility. Child Abuse \& Neglect, 22, 1239-1252.

Berliner, L. (2011). Child sexual abuse: Definitions, prevalence, and consequences. In J. E. B. Myers (Ed.), The APSAC handbook on child maltreatment (pp. 215232). Thousand Oaks, CA: Sage.

Brank, E. M., \& Wylie, L. E. (2014). Differing perspectives on older adult caregiving. Journal of Applied Gerontology, 1, 1-23. doi:10.1177/0733464813517506 
Broussard, S. D., \& Wagner, W. G. (1988). Child sexual abuse: Who is to blame? Child Abuse \& Neglect, 12, 663-569.

Campbell, R., Dworkin, E., \& Cabral, G. (2009). An ecological model of the impact of sexual assault on women's mental health. Trauma, Violence, \& Abuse, 10, 225-246.

Celano, M., Hazzard, A., Campbell, S., \& Lang, C. (2002). Attribution retraining with sexually abused children: Review of techniques. Child Maltreatment, 7 , 65-76.

Cohen, J. A., \& Mannarino, A. P. (2000). Predictors of treatment outcome in sexually abused children. Child Abuse \& Neglect, 24, 983-994.

Collings, S. J. (1997). Development, reliability, and validity of the Child Sexual Abuse myth scale. Journal of Interpersonal Violence, 12, 665-674.

Craven, S., Brown, S., \& Gilchrist, E. (2006). Sexual grooming of children: Review of literature and theoretical considerations. Journal of Sexual Aggression, 12, 287-299.

Cuevas, C. A., Finkelhor, D., Turner, H. A., \& Ormrod, R. K. (2007). Juvenile delinquency and victimization. Journal of Interpersonal Violence, 22, 1581-1602.

Davies, M., \& Rogers, P. (2006). Perceptions of male victims in depicted sexual assaults: A review of the literature. Aggression and Violent Behavior, 11, 367-377.

Davies, M., \& Rogers, P. (2009). Perceptions of blame and credibility toward victims of childhood sexual abuse: Differences across victim age, victimperpetrator relationship, and respondent gender in a depicted case. Journal of Child Sexual Abuse, 18, 78-92.

Esnard, C., \& Dumas, R. (2013). Perceptions of male victim blame in a child sexual abuse case: Effects of gender, age and need for closure. Psychology, Crime \& Law, 19, 817-844.

Feiring, C., Taska, L., \& Chen, K. (2002). Trying to understand why horrible things happen: Attribution, shame, and symptom development following sexual abuse. Child Maltreatment, 7, 26-41.

Ford, H. H., Schindler, C. B., \& Medway, F. J. (2001). School professionals' attributions of blame for child sexual abuse. Journal of School Psychology, 39, 25-44.

Goodman-Brown, T. B., Edelstein, R. S., Goodman, G. S., Jones, D. P. H., \& Gordon, D. S. (2003). Why children tell: A model of children's disclosure of sexual abuse. Child Abuse \& Neglect, 27, 525-540.

Graham, L., Rogers, P., \& Davies, M. (2007). Attributions in a hypothetical child sexual abuse case: Roles of abuse type, family response and respondent gender. Journal of Family Violence, 22, 733-745.

Grauerholz, L. (2000). An ecological approach to understanding sexual revictimization: Linking personal, interpersonal, and sociocultural factors and processes. Child Maltreatment, 5, 5-17.

Harding, H. G., Zinzow, H. M., Burns, E. E., \& Jackson, J. L. (2010). Attributions of responsibility in a child sexual abuse (CSA) vignette among respondents with 
CSA histories: The role of abuse similarity to a hypothetical victim. Journal of Child Sexual Abuse, 19, 171-189.

Hazzard, A., Celano, M., Gould, J., Lawry, S., \& Webb, C. (1995). Predicting symptomatology and self-blame among child sexual abuse victims. Child Abuse \& Neglect, 19, 707-714.

Hébert, M., Daigneault, I., Collin-Vézina, D., \& Cyr, M. (2007). Factors linked to distress in mothers of children disclosing sexual abuse. Journal of Nervous and Mental Disease, 195, 805-811.

Hoeve, M., Dubas, J. S., Eichelsheim, V. I., van der Laan, P. H., Smeenk, W., \& Gerris, J. R. M. (2008). The relationship between parenting and delinquency: A meta-analysis. Journal of Abnormal Child Psychology, 37, 749-775.

Hunter, J. A., Goodwin, D. W., \& Wilson, R. J. (1992). Attributions of blame in child sexual abuse victims: An analysis of age and gender influence. Journal of Child Sexual Abuse, 1, 75-89.

Ko, C., \& Koh, C. (2007). The influence of abuse situation and respondent background characteristics on Korean nurses' perceptions of child sexual abuse: A fractional factorial design. International Journal of Nursing Studies, 44, 1165-1176.

Leonard, E. W. (2013). Expecting the unattainable: Caseworker use of the "ideal" mother stereotype against the nonoffending mother for failure to protect fr 69 , 311-356.

Lerner, M. J. (1980). The belief in a just world. New York, NY: Plenum Press.

Maniglio, R. (2009). The impact of child sexual abuse on health: A systematic review of reviews. Clinical Psychology Review, 29, 647-657.

Maynard, C., \& Wiederman, M. (1997). Undergraduate students' perceptions of child sexual abuse: Effects of age, sex and gender role attitudes. Child Abuse \& Neglect, 21, 833-844.

Randall, M. (2010). Sexual assault law, credibility, and "ideal victims": Consent, resistance, and victim blaming. Canadian Journal of Women and the Law, 22, 397-434.

Rogers, P., \& Davies, M. (2007). Perceptions of credibility and attributions of blame towards victim in a childhood sexual abuse case: Gender and age factors. Journal of Interpersonal Violence, 22, 566-584.

Rogers, P., Josey, N., \& Davies, M. (2007). Victim age, attractiveness and abuse history as factors in the perception of a hypothetical child sexual abuse case. Journal of Sexual Aggression, 13, 121-137.

Rogers, P., Lowe, M., \& Boardman, M. (2014). The roles of victim symptomology, victim resistance and respondent gender on perceptions of a hypothetical child sexual abuse case. Journal of Forensic Practice, 16, 18-31.

Rogers, P., Titterington, L., \& Davies, M. (2009). Attributions of blame and credibility in a hypothetical child sexual abuse case: Roles of victim disability, victim resistance and respondent gender. International Journal of Disability, Development and Education, 56, 205-228. 
Ruggiero, K. J., Smith, D. W., Hanson, R. F., Resnick, H. S., Saunders, B. E., Kilpatrick, D. G., . . . Best, C. L. (2003). Is disclosure of childhood rape associated with mental health outcome? Results from the National Women's Study. Child Maltreatment, 9, 62-77.

Sas, L. D., Cunningham, A. H., Hurley, P., Dick, T., \& Farnsworth, A. (1995). Tipping the balance to tell the secret: Public discovery of child sexual abuse. London, Ontario, Canada: Family Court Clinic.

Shaver, K. G. (1970). Defensive attribution: Effects of severity and relevance on the responsibility assigned for an accident. Journal of Personality and Social Psychology, 14, 101-113.

Tyler, K. (2002). Social and emotional outcomes of childhood sexual abuse: A review of recent research. Aggression and Violent Behavior, 7, 567-589.

Ullman, S. (2003). Social reactions to child sexual abuse disclosures: A critical review. Journal of Child Sexual Abuse, 12, 89-121.

U.S. Department of Health and Human Services, Administration for Children and Families, Administration on Children, Youth and Families, \& Children's Bureau. (2015). Child maltreatment 2013. Retrieved from http://www. acf.hhs.gov/pro- grams/cb/research-data-technology/statistics-research/ child-maltreatment

Valle, L. A., \& Silovsky, J. F. (2002). Attributions and adjustment following child sexual and physical abuse. Child Maltreatment, 7, 9-25.

van Toledo, A., \& Seymour, F. (2013). Interventions for caregivers of children who disclose sexual abuse: A review. Clinical Psychology Review, 33, 772-781.

Waterman, C. K., \& Foss-Goodman, D. (1984). Child molesting: Variables relating to attribution of fault to victims, offenders, and nonparticipating parents. Journal of Sex Research, 20, 329-349. 